\title{
Study of Catalytic Effect of Nanolayered Montmorillonite Organoclays in Epoxy Polymer
}

\author{
T. P. Mohan and K. Kanny \\ Composites Research Group, Department of Mechanical Engineering, Durban University of Technology, Durban 4000, South Africa
}

Correspondence should be addressed to K. Kanny, kannyk@dut.ac.za

Received 27 May 2011; Accepted 12 July 2011

Academic Editors: E. Cattaruzza, T. Pal, A. Swami, and C.-S. Yeh

Copyright ( $\odot 2011$ T. P. Mohan and K. Kanny. This is an open access article distributed under the Creative Commons Attribution License, which permits unrestricted use, distribution, and reproduction in any medium, provided the original work is properly cited.

\begin{abstract}
This paper is about the study of catalytic effect of nanolayered montmorillonite- (MMT-) based organoclays (OCs) in epoxy polymer by directly monitoring their exothermic temperature versus time during curing. Untreated clays (UCs) of MMT were also filled in the epoxy polymer for comparative study. OCs and UCs were individually filled in epoxy polymer from 0 wt. $\%$ to $5 \mathrm{wt} . \%$, and the curing characteristics were examined. The cure behavior of epoxy-OC composites changes as a function of OC concentration. Among the epoxy-OC systems, improved curing reaction was observed at $3 \mathrm{wt} . \%$ OC-filled epoxy composites. Addition of OC above $3 \mathrm{wt}$ \% in epoxy reduces its catalytic effect due to presence of two types of cross-linking, namely, intergallery and extragallery cross-linking reactions. The curing behaviours of epoxy-UC composites were almost similar to those of pure epoxy polymer, and hence the results suggest that UC does not act as catalyst in epoxy polymer. The cured composite series was examined by studying their structure and morphology using X-ray diffraction (XRD), transmission electron microscopy (TEM) analysis, and the Fourier transform infrared (FTIR) spectroscopy.
\end{abstract}

\section{Introduction}

In polymer nanocomposites, polymer filled with montmorillonite- (MMT-) based clay is an important area of research interest in the recent past. These polymer clay nanocomposites (PCNs) show improved mechanical (tensile, hardness, impact, etc.), thermal (thermal stability, reduced weight loss at higher temperature, Tg, etc.), and physical properties (optical, dimensional stability, damping, barrier properties, etc.) at a very low clay concentration $(\sim 5 \mathrm{wt} . \%)$ in the polymer. Their unique phase morphology, clay polymer interactions, compatibility with most of the polymers, low clay concentration, low cost, and easier processing methods had tempted researchers to gain significant interest in these polymer clay nanocomposites.

The nanolayered silicate clays that are used as reinforcement fillers in polymer are generally MMT-based aluminosilicate clays. MMT clays are hydrophilic and hence do not provide proper reinforcing/filling effect to the hydrophobicbased organic polymer matrices. Therefore, before reinforcing MMT clays in polymer matrix, MMT clays have to be converted from hydrophilic to hydrophobic. This conversion can be accomplished by replacing the exchangeable ion $\left(\mathrm{Na}^{+}\right)$ present in the interlayer space of the MMT clay with the organic cations. Commonly used organic cations for MMT clay modifications are onium- or quaternary-ammoniumbased salts, and such type of organo modified clay is known as organoclays. When these organotreated MMTbased organoclays are filled into the host polymer matrix, two types of morphologies will form, namely, intercalated and delaminated/exfoliated nanocomposite structure. The intercalated structure is a well-ordered multilayered structure of silicates, where the polymer chains are just inserted into the interlayer spaces (intergallery region). On the other hand, in the exfoliated/delaminated structure, the polymer chains separate individual silicate layers well apart, for example, $80-100 \AA$ or more, and no longer close enough to interact with each other's layers. Sometimes in exfoliated structure, nanolayers are randomly dispersed in matrix polymer. The aspect ratio (length/thickness) of individual nanolayer of clay is very high in the order of several hundreds to thousands and therefore contributes to the improved mechanical properties in polymer system along the loading direction and also serves as an impermeable medium 
when the host polymer is exposed to the gas/moisture medium. The maximum utilization of this aspect ratio is fully exploited by an exfoliated structure of PCN composites rather than an intercalated structure. Hence, achieving an exfoliated structure is a real challenge in this PCN system, even though various polymers are used in recent years [1-7].

Epoxy-clay nanocomposites (ECNs) are an important area of research interest in the thermoset-based polymer nanocomposites. Several literature reports are available on epoxy-clay nanocomposites showing improved water barrier, mechanical, and thermal properties [8-14]. These properties in ECN are based on some important parameters, namely, clay concentration in matrix polymer, intercalated and exfoliated nanocomposite structures. These parameters are governed by curing characteristics. Hence understanding the curing behaviour is important as it controls the properties and structure of nanocomposites. In addition to this, the literature also states that the organoions of the organoclays that were present in the intergallery regions of clays will readily react with the epoxide monomer by ring opening polymerization of onium ions with the epoxy ring. These organoclays act as catalysis and hence control the curing characteristic of ECN. This shows that the curing of organoclays with epoxy resin, clay concentration, epoxy curing with hardener, and so forth controls the structure (intercalation or exfoliation) of composites' interaction and exfoliation structures in epoxy-clay nanocomposites, and hence understanding the cure behaviour of ECN is an important phenomenon.

In the literature, very few articles are available discussing the curing studies and characteristics of ECN. The curing characteristics are studied by using differential scanning calorimetry (DSC) [15], dynamic mechanical analysis (DMA) [16], Rheology [17], and electrical measurements [18]. Chen and He [19] studied the curing behaviour of epoxy-clay nanocomposites using cure meter which measures torque during gelling with respect to time. $\mathrm{Xu}$ et al. [20] studied the cure behaviour of epoxy-clay nanocomposites using Flory's gelation theory. This paper is about the direct online study of curing behaviour of epoxy-clay nanocomposites by measuring the exothermic temperature with respect to time. Epoxy polymer starts curing or cross-linking after the addition of hardener (or curing agents). During this curing reaction, the temperature of resin increases rapidly due to exothermic reaction and also resin becomes more viscous and eventually becomes harder. The addition of clay in epoxy-hardener system will change the temperature-time curing behaviour from the unfilled epoxy curing. Hence, studying the changes in temperature versus time for nanocomposite series during curing will provide more insight about the role played by the organoclays in epoxy polymer, concentration of clays, and intercalation-exfoliation structures in nanocomposites.

\section{Experimental Details}

2.1. Materials. The matrix material used in this system is DGEBA epoxy resin system, and the curing agent is triethylene tetramine (TETA), both obtained from CIBA Ltd, Basle,
Switzerland. The reinforcement fillers in matrix are $\mathrm{Na}^{+}$ montmorillonite-untreated clay (UC) and an organoclay (OC). The organoclay is alkyl-ammonium-treated MMT clay obtained from Southern Clay Products Ltd, Gonzalez, Tex, USA, supplied under the trade name Cloisite 30B.

2.2. Nanocomposite Preparation. Initially the desired amount of epoxy resin was taken, and then the clay was gently added in to the resin bath. Mixing of clay and epoxy was carried out by mechanical shear mixer. The mixer rotates at $500 \mathrm{rpm}$, and mixing was carried out for $2 \mathrm{~h}$. After uniform mixing of clay and resin, TETA hardener was mixed into the resinclay solution. The resin to hardener ratio was maintained at $3: 1$ and then cast in the mold. The nanocomposite specimens synthesized by this method are tested for various characterizations.

2.3. Characterization. Curing characteristics of epoxy and epoxy-filled OC and UC series were studied by directly monitoring the exothermic cure temperature at regular time intervals. The resin and hardener contents were maintained unchanged for all the composite series during curing temperature-time measurements. The temperature of the curing reaction was monitored at regular intervals, and the time-temperature graph was plotted for all the curing sample series. The room temperature was maintained at $23^{\circ} \mathrm{C} \pm 2^{\circ} \mathrm{C}$. $\mathrm{XRD}$ was performed to evaluate the degree of intercalation/exfoliation of nanocomposites. XRD was carried out with a scanning rate of $2 \%$ min with $\mathrm{Cu} \mathrm{K} \alpha$ radiation $(\lambda=1.5401 \AA)$ operating at $30 \mathrm{KV}$ and $15 \mathrm{~mA}$. Thin sections of sample were made for TEM-Philip electron microscopy operating at $200 \mathrm{KV}$. Tensile testing was carried out using Instron machine at a cross-head speed of $1 \mathrm{~mm} / \mathrm{min}$ according to ASTM D638. FTIR (Nicolet) was performed using an attenuated total reflectance (ATR) mode to study the functional group of epoxy and was also used to measure the degree of cure using the peak value of epoxy oxirane ring as measured elsewhere [21].

\section{Results and Discussions}

3.1. Structure and Curing Characteristics. Figure 1 shows the time-temperature curing curve of epoxy and UC-filled epoxy composite series. The result shows that the maximum curing temperature and time for unfilled epoxy is at $76^{\circ} \mathrm{C}$ and 95 minutes, respectively. Addition of UC clays to epoxy polymer did not change the curing time and curing curve patterns; however, the peak curing temperature was less than that of epoxy polymer. The peak curing temperature of epoxy resin continuously decreased as UC content continuously increased in epoxy polymer. The reduction in curing temperature of epoxy-UC series is due to the lesser concentration of epoxy polymer due to increasing concentration of clay content in it. This low-epoxy-polymer-matrix-content composites release low amount of heat during curing which in turn gives reduced exothermic curing peak temperature. Figure 2 shows the time-temperature curing curve of epoxy and OC-filled epoxy series. The curing curves of OC-filled 


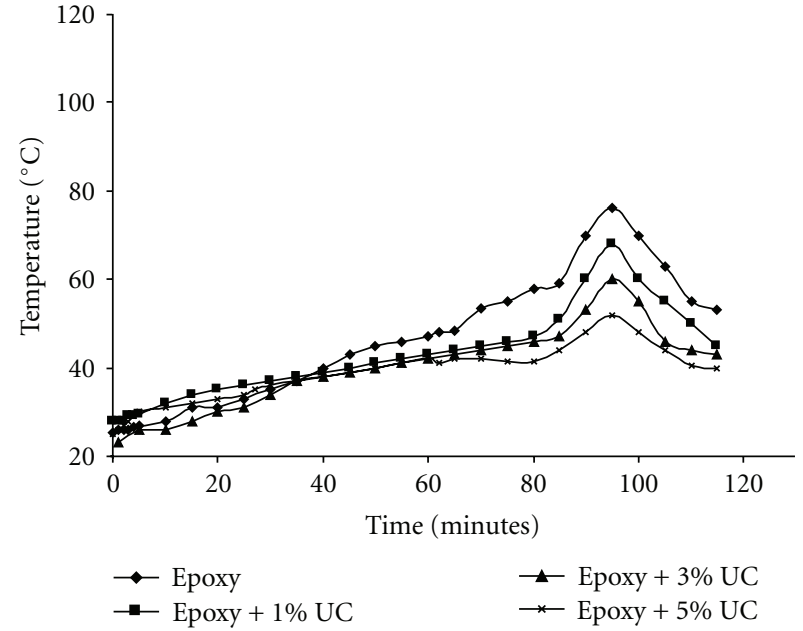

FIGURE 1: Time-temperature curing curves of epoxy-UC composite series.

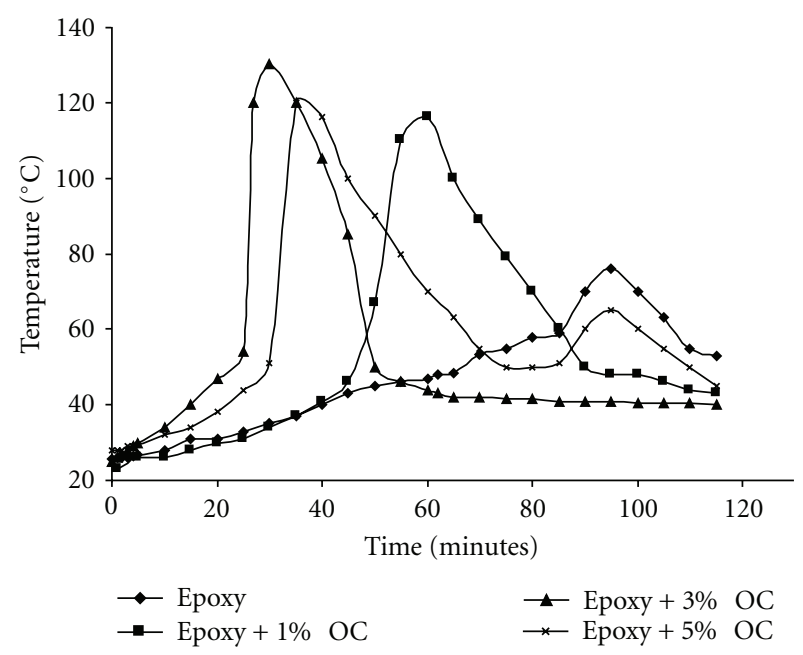

FIGURE 2: Time-temperature curing curves of epoxy-OC composite series.

epoxy series show different curing curve patterns than those of epoxy and UC-filled epoxy polymer composites.

In epoxy with $1 \% \mathrm{OC}$, the maximum curing temperature and time was observed at $116^{\circ} \mathrm{C}$ and 60 minutes, respectively. This result shows that the curing occurs at much faster rate than that of epoxy polymer. The onium ions of the organoclay can readily participate in curing reaction of epoxide group along with TETA hardener. This increases the degree of cure as observed by FTIR studies. As OC reduces the curing time of epoxy polymer, it acts as a catalyst due to the presence of onium ions. Epoxy with $3 \mathrm{wt} . \%$ OC shows, further reduction in the cure time, and the maximum curing temperature and time were observed at $130^{\circ} \mathrm{C}$ and 30 minutes respectively. The degree of cure is higher for epoxy-3\% OC composites due to the presence of higher concentration of onium ions (Table 1). Higher addition of OC above 3 wt.\% in epoxy polymer shows different curing behaviour. Epoxy-5 wt.\% OC shows two different curing
TABLE 1: Degree of cure $(\alpha)$ of epoxy clay series.

\begin{tabular}{lcc}
\hline Material & E + OC series & E + UC series \\
\hline Epoxy & 0.71 & 0.71 \\
Epoxy $+1 \%$ clay & 0.74 & 0.72 \\
Epoxy $+3 \%$ clay & 0.79 & 0.71 \\
Epoxy $+5 \%$ clay & 0.81 & 0.69 \\
\hline
\end{tabular}

peak curves, one peak curve at reduced temperature and another curing peak curve at the epoxy curing temperature. The low curing temperature took more time ( 35 minutes) and low peak temperature $\left(120^{\circ}\right)$ than that of $3 \mathrm{wt} . \%$ OCfilled epoxy composites. This shows reduced catalytic effect of OC at higher concentration (5 wt.\%). The two distinct curing peaks for $5 \mathrm{wt} . \%$ OC-filled epoxy composites are possibly due to the two types of curing reactions occurring in the composites, one at intergallery regions of clays where onium ions react with intercalated epoxy resin and another at the extragallery regions (matrix) where epoxy and hardener react with each other to form a cured polymer. The imbalance in these two reactions (intergallery and extragallery) in higher OC content (5wt.\%) causes two distinct time-temperature curing patterns (Figure 2). The UC addition in epoxy polymer does not alter the curing time or the degree of cure, and this suggests that the UC does not show catalytic effect in polymer matrix system. Similar trends in OC- and UC-filled composites were observed in our earlier studies which were examined using DSC and rheology studies $[22,23]$. Furthermore, the effect of OC and UC clay addition on composites' structure is examined by using XRD and TEM methods.

The structure and morphological distribution of OC and UC in the epoxy matrix polymer were examined using XRD and TEM methods. Figure 3 shows the XRD patterns of clay and clay-filled composite series. XRD pattern of OC shows a sharp reflection peak at $2 \theta=4.92^{\circ}$ that corresponds to an interlayer spacing $(d)$ of $17.5 \AA$ (calculated from Bragg's diffraction method using the formula $2 d \sin \theta=n \lambda$ ). The XRD pattern of OC-filled epoxy polymer show different patterns. For 5 wt.\% OC in epoxy, the reflection peak shifted to lower angle of $4.42^{\circ}$, and hence the interlayer spacing $(d)$ of clay increased to $21.5 \AA$. This result shows that the matrix polymer has entered into the interlayer spacing of nanoclay and increased the $d$-spacing. Such type of structure is called an intercalated nanocomposite structure. XRD patterns of epoxy with $1 \mathrm{wt} . \%$ and $3 \mathrm{wt} . \%$ OC do not show any reflection peaks. The absence of reflection peak in $1 \mathrm{wt} . \%$ and $3 \mathrm{wt} . \%$ OC-filled composites suggests staked arrangement of nanolayers that are well apart from diffraction or randomly dispersed in polymer matrix (exfoliated structure) or may be due to the lower clay concentration in polymer matrix so that XRD reflection is absent. $\mathrm{Na}^{+}$Cloisite clay (UC) shows the diffraction peak at $7.58^{\circ}$ and corresponds to the interlayer spacing of $11.68 \AA$. XRD patterns of epoxy with $5 \mathrm{wt} . \%$ UCfilled composite also show the reflection peak at $7.58^{\circ}$, and this suggests that the matrix polymer has not entered the interlayer spacing and hence did not form an intercalated or exfoliated structure. This result further suggests that the UC 


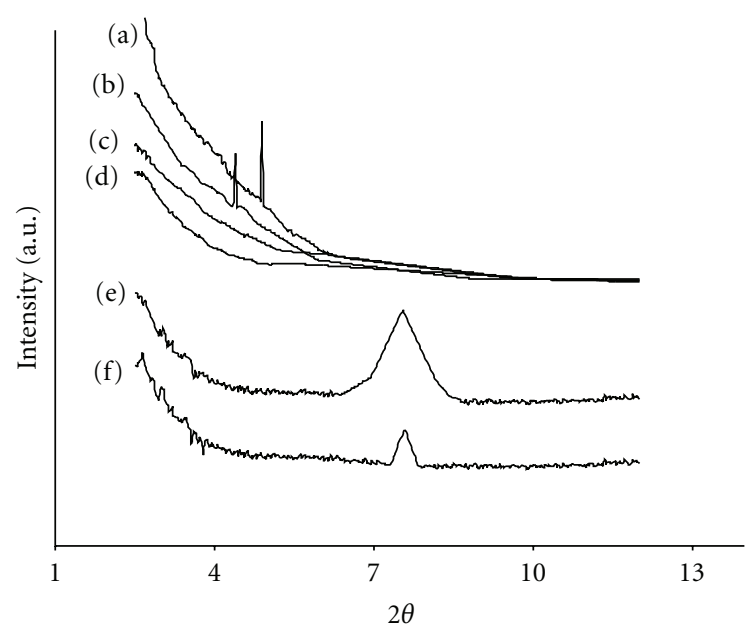

Figure 3: XRD pattern of organoclay (a), epoxy with 5 wt.\% (b), 3 wt. $\%$ (c), and 1 wt.\% (d) OC, respectively, $\mathrm{Na}^{+}$clay (UC) (e), and epoxy with 5 wt.\% UC (f).

acts as a microscale filler in epoxy polymer and does not form nanolayer dispersions like OC.

Figure 4 shows a bright field TEM picture of the composite series. In the TEM picture, the bright region is the matrix phase, while the dark region is the particle (clay) phase. Composite with $3 \mathrm{wt} . \%$ OC shows well separated and random arrangement of clay nanolayers which is an exfoliated structure. However, composite with $5 \mathrm{wt} . \%$ OC shows the staked or parallel arrangement of nanolayers in epoxy polymer matrix, and this structure is called intercalated nanocomposite structure. TEM with $5 \mathrm{wt} . \%$ UC does not show any nanolayer dispersions in epoxy polymer, and hence UC acts as a microparticle filler in the epoxy polymer matrix. The structural analysis of composites by XRD and TEM methods correlates well to each other. The optical image analysis of $5 \mathrm{wt} . \%$ OC-filled epoxy TEM pictures shows that the average separation of nanolayers of clays is $2 \mathrm{~nm}$, and this result also well correlates with the XRD result.

When the curing characteristics of composites were examined with respect to their structure (XRD and TEM), a good correlation between structure and curing was observed. In epoxy-OC series, for OC at $5 \mathrm{wt} . \%$, the nanocomposite forms intercalated structure. If we observe the curing curve of $5 \mathrm{wt} . \%$ OC-filled epoxy composites, it shows two distinct curing peaks, one at low temperature and another one at higher temperature (epoxy curing). This result further shows that intergallery polymerization occurs quicker than that of extragallery polymerization. As the curing was completed in intergallery polymerization, the clay nanolayers cannot separate each other apart in matrix which restricts their dispersion as well as the formation of exfoliated structure. However, in the composites with low OC content $(<5$ wt.\%), the curing curve shows single peak which suggests that the curing occurs uniformly throughout the composite system, and hence there is good balance among clay nanolayer separation (exfoliation), curing, and clay concentration which leads to the formation of exfoliated nanocomposite

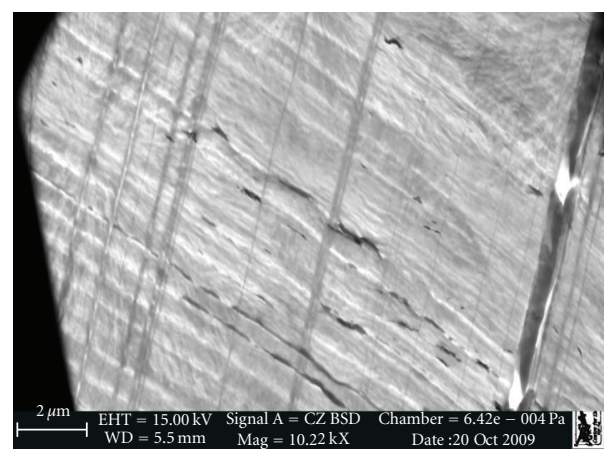

(a)

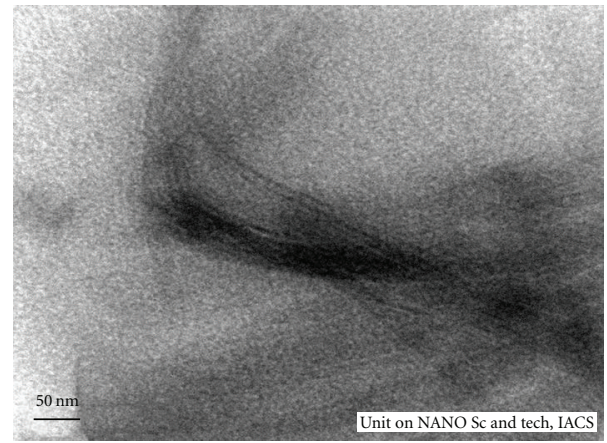

(b)

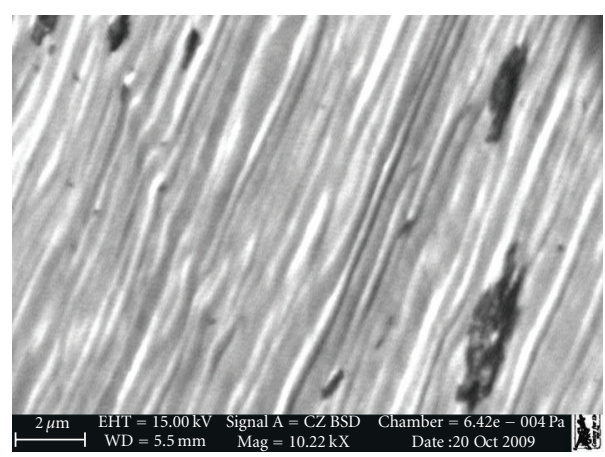

(c)

Figure 4: TEM pictures of epoxy with (a) 3 wt.\% OC, (b) 5 wt. $\%$ OC, and (c) 5 wt.\% UC.

structure. To further understand the curing characteristics of epoxy and epoxy clay series, FTIR spectrum was taken and studied.

Figure 5 shows the FTIR spectrum of epoxy and epoxyOC composite series. Epoxy shows absorption peak values at $4679 \mathrm{~cm}^{-1}$ (phenyl ring), $4621 \mathrm{~cm}^{-1}$ (phenyl ring), $4528 \mathrm{~cm}^{-1}$ (oxirane), and $3050 \mathrm{~cm}^{-1}$ (CH stretching vibration of oxirane). Oxirane peak intensity values decrease as the degree of cure of epoxy-OC composites increases. It was observed that the oxirane peak intensity value continuously reduces when the OC clay content continuously increases in the epoxy polymer matrix. In epoxy-OC composite series, the new peak was observed at $3521 \mathrm{~cm}^{-1}$ which corresponds to the characteristic group of onium ions of organoclays. Table 1 shows the degree of cure of the composite series; it 
TABLE 2: Tensile properties of epoxy and epoxy-clay composite series.

\begin{tabular}{|c|c|c|c|c|c|c|}
\hline \multirow{2}{*}{ Material } & \multicolumn{3}{|c|}{ Epoxy + OC series } & \multicolumn{3}{|c|}{ Epoxy + UC series } \\
\hline & Modulus, GPa & Strain at break, $\%$ & Strength, MPa & Modulus, GPa & Strain at break, \% & Strength, MPa \\
\hline Epoxy & 1.00 & 4.2 & 37.0 & 1.0 & 4.20 & 37.0 \\
\hline Epoxy $+1 \%$ clay & 1.20 & 4.6 & 38.0 & 1.1 & 4.35 & 38.5 \\
\hline Epoxy $+3 \%$ clay & 1.91 & 5.1 & 40.5 & 1.2 & 4.42 & 40.2 \\
\hline Epoxy $+5 \%$ clay & 1.51 & 4.7 & 39.0 & 1.3 & 4.73 & 41.3 \\
\hline
\end{tabular}

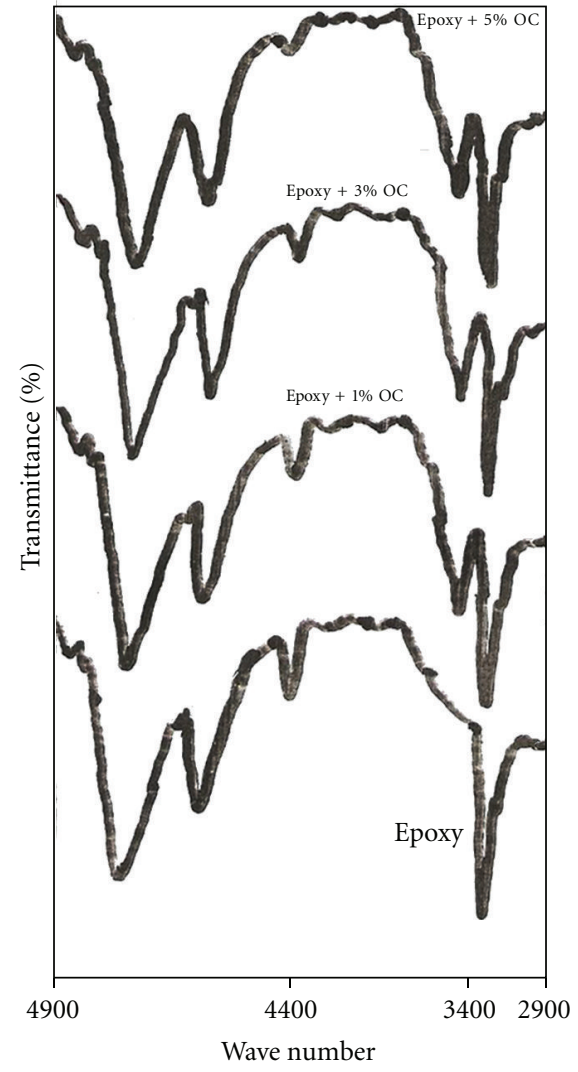

FIGURE 5: FTIR spectrum of epoxy and epoxy-OC series.

shows that the degree of cure continuously increases as the OC clay content continuously increases in the epoxy matrix, whereas no change in degree of cure was observed when UC was filled in epoxy composites. The degree of cure is measured by measuring the fraction of peak intensity value of oxirane ring of uncured epoxy resin and cured epoxy resin. As the OC content increases in the epoxy polymer, the organoions of OC react with epoxy oxirane rings and reduce the peak intensity values of oxirane rings due to less concentrations of oxirane rings in epoxy-OC cured system. The fraction of this reduced intensity values of oxirane rings of epoxy-OC composite series to that of uncured oxirane value of epoxy resin results in high degree of cure. This result shows that the onium ions of the organoclay reacts with oxirane ring of epoxide group and hence increases the degree of cure.

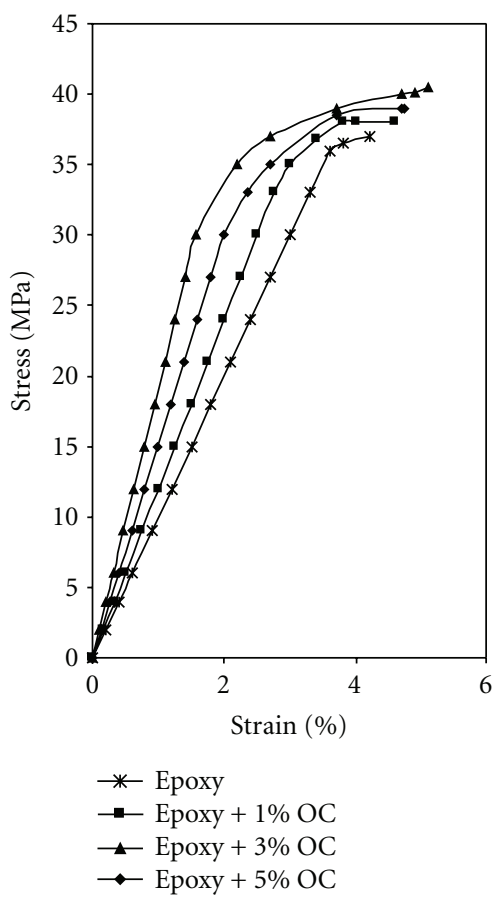

FIgure 6: Tensile stress-strain curves of epoxy and epoxy-OC composite series.

3.2. Tensile Properties. Figures 6 and 7 show the tensile stress strain curves of epoxy and epoxy filled with OC and UC composite series. The result shows that the addition of OC increases the tensile modulus, and elongation and strength of epoxy polymer. However the addition of UC in epoxy polymer resulted in moderate improvement in modulus, elongation and strength values. The tensile values are shown in Table 2. The result shows that the maximum increase in properties has been observed at $3 \mathrm{wt} . \%$ OCfilled epoxy composites. The addition of OC above $3 \mathrm{wt} . \%$ shows reduction in tensile properties, due to the formation of intercalated nanocomposite structure. Exfoliated structure provides improved properties than intercalated structure due to the large nanolayer clay surface exposure. Exfoliated structure provides increased aspect ratio (length/thickness) of nanolayered clay than that of intercalated structure at same clay volume concentration in matrix. The increased aspect ratio and surface area interaction could have caused improved strength at $3 \mathrm{wt} . \%$ OC-filled epoxy composites due to exfoliated structure. 


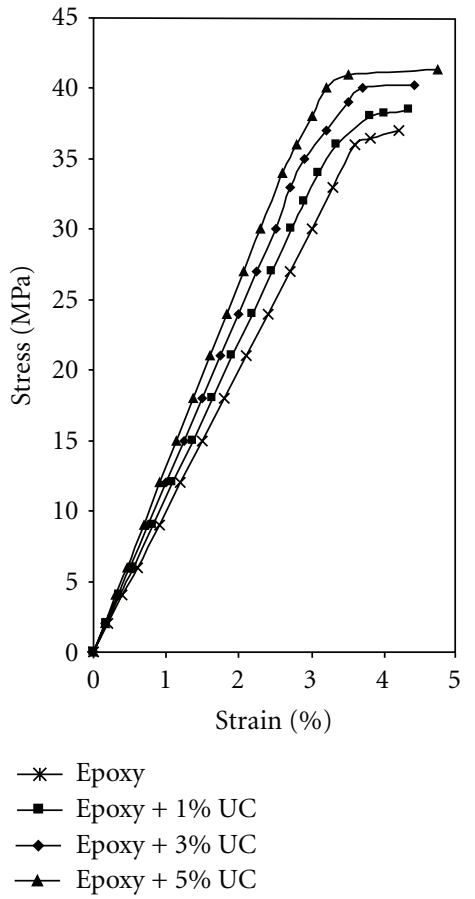

FIGURE 7: Tensile stress-strain curves of epoxy and epoxy-UC series.

\section{Conclusions}

In this work, the catalytic effect of organoclays in epoxy polymer was examined by directly monitoring the curing temperature and time patterns of unfilled and clay-filled epoxy resins. The catalytic effect of organotreated montmorillonite clay in epoxy polymer was studied by varying the clay content and observed that maximum catalytic effect was observed at $3 \mathrm{wt} . \%$ OC content. Higher addition of OC (5wt.\%) in epoxy matrix reduces the catalytic effect and shows the formation of intercalated nanocomposite structure due to improper curing at intergallery and extragallery region of epoxy polymer. The addition of untreated montmorillonite clay in epoxy polymer does not show any catalytic effect and acts as micron-scale filler in epoxy polymer. An improved tensile property was observed in OCfilled composites when compared with unfilled epoxy and UC-filled epoxy composites.

\section{Acknowledgment}

The authors gratefully acknowledge the National Research Foundation (NRF) of South Africa for its financial support (Grant no.: 71599-2010) in carrying out this work.

\section{References}

[1] D. Sikdar, D. R. Katti, K. S. Katti, and R. Bhowmik, "Insight into molecular interactions between constituents in polymer clay nanocomposites," Polymer, vol. 47, no. 14, pp. 5196-5205, 2006.
[2] B. Xu, Q. Zheng, Y. Song, and Y. Shangguan, "Calculating barrier properties of polymer/clay nanocomposites: effects of clay layers," Polymer, vol. 47, no. 8, pp. 2904-2910, 2006.

[3] P. Kiliaris and C. D. Papaspyrides, "Polymer/layered silicate (clay) nanocomposites: an overview of flame retardancy," Progress in Polymer Science, vol. 35, no. 7, pp. 902-958, 2010.

[4] P. Meneghetti and S. Qutubuddin, "Synthesis, thermal properties and applications of polymer-clay nanocomposites," Thermochimica Acta, vol. 442, no. 1-2, pp. 74-77, 2006.

[5] X. Yi, H. L. Duan, Y. Chen, and J. Wang, "Prediction of complex dielectric constants of polymer-clay nanocomposites," Physics Letters, Section A, vol. 372, no. 1, pp. 68-71, 2007.

[6] Y. Mansoori, S. V. Atghia, M. R. Zamanloo, G. Imanzadeh, and M. Sirousazar, "Polymer-clay nanocomposites: free-radical grafting of polyacrylamide onto organophilic montmorillonite," European Polymer Journal, vol. 46, no. 9, pp. 1844$1853,2010$.

[7] A. J. Bur, Y. H. Lee, S. C. Roth, and P. R. Start, "Measuring the extent of exfoliation in polymer/clay nanocomposites using real-time process monitoring methods," Polymer, vol. 46, no. 24, pp. 10908-10918, 2005.

[8] P. I. Xidas and K. S. Triantafyllidis, "Effect of the type of alkylammonium ion clay modifier on the structure and thermal/mechanical properties of glassy and rubbery epoxyclay nanocomposites," European Polymer Journal, vol. 46, no. 3, pp. 404-417, 2010.

[9] W. Liu, S. V. Hoa, and M. Pugh, "Water uptake of epoxy-clay nanocomposites: model development," Composites Science and Technology, vol. 67, no. 15-16, pp. 3308-3315, 2007.

[10] X. Kornmann, H. Lindberg, and L. A. Berglund, "Synthesis of epoxy-clay nanocomposites. Influence of the nature of the curing agent on structure," Polymer, vol. 42, no. 10, pp. 44934499, 2001.

[11] I. Zaman, Q. H. Le, H. C. Kuan et al., "Interface-tuned epoxy/clay nanocomposites," Polymer, vol. 52, no. 2, pp. 497504, 2010.

[12] H. Tan, J. Han, G. Ma, M. Xiao, and J. Nie, "Preparation of highly exfoliated epoxy-clay nanocomposites by sol-gel modification," Polymer Degradation and Stability, vol. 93, no. 2, pp. 369-375, 2008.

[13] S. A. Gârea, H. Iovu, and G. Voicu, "The influence of some new montmorillonite modifier agents on the epoxymontmorillonite nanocomposites structure," Applied Clay Science, vol. 50, no. 4, pp. 469-475, 2010.

[14] J. P. Yang, G. Yang, G. Xu, and S. Y. Fu, "Cryogenic mechanical behaviors of MMT/epoxy nanocomposites," Composites Science and Technology, vol. 67, no. 14, pp. 2934-2940, 2007.

[15] G. M. Kim, H. Qin, X. Fang, F. C. Sun, and P. T. Mather, "Hybrid epoxy-based thermosets based on polyhedral oligosilsesquioxane: cure behavior and toughening mechanisms," Journal of Polymer Science, Part B, vol. 41, no. 24, pp. 3299-3313, 2003.

[16] Y. Sun, Z. Zhang, K. S. Moon, and C. P. Wong, "Glass transition and relaxation behavior of epoxy nanocomposites," Journal of Polymer Science, Part B, vol. 42, no. 21, pp. 38493858, 2004.

[17] P. Butzloff, N. A. D’Souza, T. D. Golden, and D. Garrett, "Epoxy + montmorillonite nanocomposite: effect of composition on reaction kinetics," Polymer Engineering and Science, vol. 41, no. 10, pp. 1794-1802, 2001.

[18] F. Hussain, J. Chen, and M. Hojjati, "Epoxy-silicate nanocomposites: cure monitoring and characterization," Materials Science and Engineering A, vol. 445-446, pp. 467-476, 2007. 
[19] D. Chen and P. He, "Monitoring the curing process of epoxy resin nanocomposites based on organo-montmorillonite- a new application of resin curemeter," Composites Science and Technology, vol. 64, no. 16, pp. 2501-2507, 2004.

[20] W. B. Xu, Z. F. Zhou, P. S. He, and W. P. Pan, "Cure behavior of epoxy Resin/MMT/DETA nanocomposite: resin curemeter," Journal of Thermal Analysis and Calorimetry, vol. 78, no. 1, pp. 113-124, 2004.

[21] M. A. Escola, C. A. Moina, A. C. N. Gómez, and G. O. Ybarra, "The determination of the degree of cure in epoxy paints by infrared spectroscopy," Polymer Testing, vol. 24, no. 5, pp. 572575, 2005.

[22] T. P. Mohan, M. R. Kumar, and R. Velmurugan, "Rheology and curing characteristics of epoxy-clay nanocomposites," Polymer International, vol. 54, no. 12, pp. 1653-1659, 2005.

[23] T. P. Mohan, R. Velmurugan, and K. Kanny, "Epoxy-clay nanocomposites: effect of curing temperature in mechanical properties," International Journal of Plastics Technology, vol. 13, no. 2, pp. 123-132, 2009. 

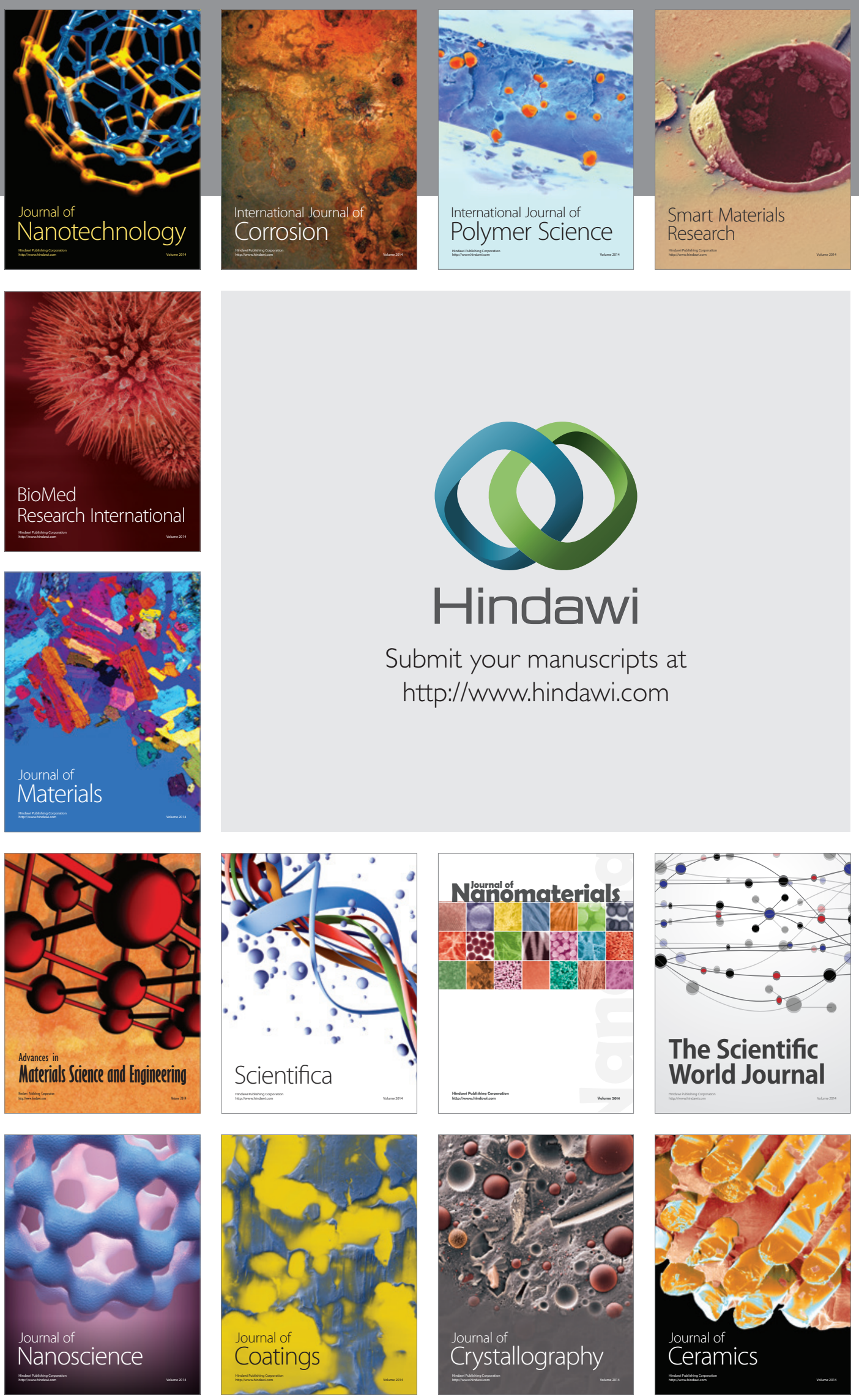

The Scientific World Journal

Submit your manuscripts at

http://www.hindawi.com

\section{World Journal}

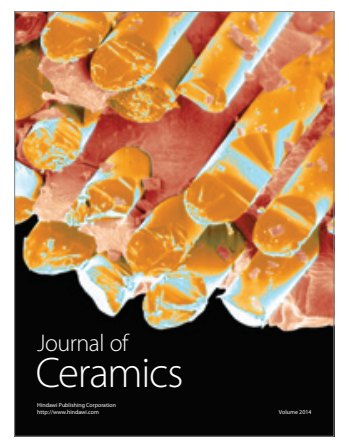

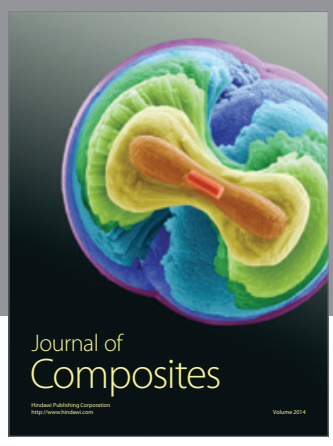
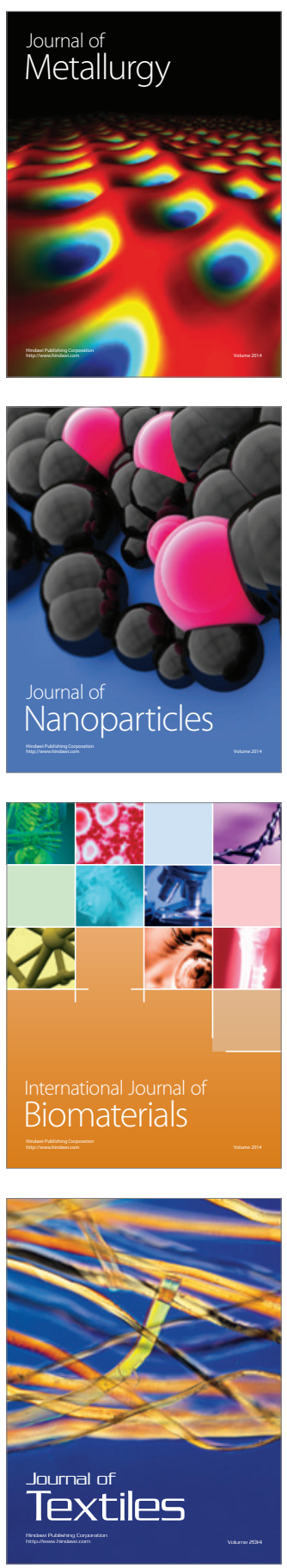